\title{
VIEWPOINT
}

\section{Concepts in hypoxia reborn}

\author{
Daniel S Martin ${ }^{* 1,2}$, Maryam Khosravi', Mike PW Grocott',3 and Michael G Mythen ${ }^{2,4}$
}

\begin{abstract}
The human fetus develops in a profoundly hypoxic environment. Thus, the foundations of our physiology are built in the most hypoxic conditions that we are ever likely to experience: the womb. This magnitude of exposure to hypoxia in utero is rarely experienced in adult life, with few exceptions, including severe pathophysiology in critical illness and environmental hypobaric hypoxia at high altitude. Indeed, the lowest recorded levels of arterial oxygen in adult humans are similar to those of a fetus and were recorded just below the highest attainable elevation on the Earth's surface: the summit of Mount Everest. We propose that the hypoxic intrauterine environment exerts a profound effect on human tolerance to hypoxia. Cellular mechanisms that facilitate fetal well-being may be amenable to manipulation in adults to promote survival advantage in severe hypoxemic stress. Many of these mechanisms act to modify the process of oxygen consumption rather than oxygen delivery in order to maintain adequate tissue oxygenation. The successful activation of such processes may provide a new chapter in the clinical management of hypoxemia. Thus, strategies employed to endure the relative hypoxia in utero may provide insights for the management of severe hypoxemia in adult life and ventures to high altitude may yield clues to the means by which to investigate those strategies.
\end{abstract}

\section{Introduction}

In the early 20th century, after extensive studies of the ovine fetal circulation, Sir Joseph Barcroft (1872-1947) postulated that the environment in which the human fetus develops would be comparable to that likely endured by an adult on the summit of Mount Everest $[1,2]$. He termed this intriguing hypothesis 'Everest

\footnotetext{
*Correspondence: daniel.martin@ucl.ac.uk

${ }^{1}$ Centre for Altitude, Space and Extreme Environment Medicine, Portex Unit, University College London Institute of Child Health, 30 Guilford Street, London, WC1N 1EH, UK

Full list of author information is available at the end of the article
}

in utero' and proposed that to survive the hypoxic uterine environment the fetus must develop elaborate physiological strategies comparable to those seen in climbers ascending the great Himalayan peaks.

In 2007, four climbers descending from the summit of Mount Everest ( 8,848 meters) took arterial blood gases from one another at 8,400 meters above sea level. Their mean arterial partial pressure of oxygen $\left(\mathrm{PaO}_{2}\right)$ was $3.28 \mathrm{kPa}(24.6 \mathrm{~mm} \mathrm{Hg})$ with a mean calculated arterial oxygen saturation $\left(\mathrm{SaO}_{2}\right)$ of $54 \%$ while they rested without supplemental oxygen [3]. Among this group, one individual had $\mathrm{a} \mathrm{PaO}_{2}$ of $2.55 \mathrm{kPa}(19.1 \mathrm{~mm} \mathrm{Hg})$, the lowest $\mathrm{PaO}_{2}$ ever reported in an adult human. So how far removed from intrauterine life were these measurements, and do climbers exhibit, as does the fetus, physiological strategies that may benefit the similarly hypoxemic critically ill patient?

\section{From Barcroft's sheep to mice and men}

The overwhelming challenge for a developing fetus is its complete reliance on the maternal circulation for oxygenation via placental transfer. The fetus therefore competes with other maternal organs for a share of the systemic oxygen delivery such that increased demand from other maternal tissues could be detrimental to the fetal circulation. Extrapolations from animal studies suggest that human fetal $\mathrm{PaO}_{2}$ is between 2.5 and $3.5 \mathrm{kPa}$ $[4,5]$. Thus, Barcroft's 'Everest in utero' was a remarkably accurate prediction given the limited data available to him at the turn of the last century. Table 1 compares measurements that contribute to oxygen carriage in the fetus, the typical adult male, and climbers acclimatized to high altitude near the summit of Mount Everest. It seems an astonishing coincidence that the highest point on the Earth's surface, the limit of human tolerance of hypoxemia [6], is analogous to life in utero. Despite this degree of hypoxemia in utero, there is little evidence that anaerobic metabolism is a dominant source of fetal energy [7], suggesting that this level of fetal oxygenation is sufficient for tissue requirements.

The fetus has negligible ability to increase systemic oxygen delivery so instead must initiate mechanisms that maximize the use of available oxygen supplies. Following an acute reduction in oxygen delivery, fetal tissue oxygen extraction increases to compensate until delivery falls 
Table 1. Values pertinent to arterial oxygen carriage in the term fetus, male high-altitude climbers at 8,400 meters on Mount Everest, and typical adult male

\begin{tabular}{lccc}
\hline & Term fetus & Climbers at 8, $\mathbf{4 0 0}$ meters $^{\text {a }}$ & 'Typical' adult male \\
\hline $\mathrm{PaO}_{2^{\prime}}, \mathrm{KPa}$ & $2.5-3.5$ & 3.28 & 13.3 \\
$\mathrm{SaO}_{2^{\prime}}$ percentage & 65 & 54 & 98 \\
$\mathrm{PaCO}$ & $\mathrm{KPa}$ & 1.77 & $4.7-6.0$ \\
$\mathrm{pH}$ & $5.3-6.6$ & 7.53 & $7.35-7.45$ \\
$\mathrm{Hb}, \mathrm{g} / \mathrm{dL}$ & $7.25-7.35$ & 19.3 & 15.0 \\
$\mathrm{P50}, \mathrm{kPa}$ & 16.6 & 3.6 & 3.5 \\
$\mathrm{CaO}_{2^{\prime}} \mathrm{mL} / \mathrm{L}$ & 2.5 & 145 & 200
\end{tabular}

${ }^{\mathrm{a}} \mathrm{Grocott}$ and colleagues [3]. $\mathrm{CaO}_{2}$, arterial oxygen content; $\mathrm{Hb}$, hemoglobin concentration; $\mathrm{P} 50$, the arterial partial pressure of oxygen at which $50 \%$ of hemoglobin is saturated with oxygen; $\mathrm{PaCO}_{2}$, arterial partial pressure of carbon dioxide; $\mathrm{PaO}_{2}$, arterial partial pressure of oxygen; $\mathrm{SaO} 2_{2}$, arterial oxygen saturation.

below approximately $50 \%$ of normal [8]. This increase in tissue oxygen extraction acts as a buffer before cellular oxygen consumption begins to fall, and the threshold of this consumption varies widely between different organs [9]. Once tissue oxygen extraction is maximal, there follows a marked decrease in fetal movement, particularly breathing effort and forelimb activity [10,11]. Cessation of excessive movement results in a reduced oxygen consumption, as demonstrated by the administration of neuromuscular blocking agents in experimental models [12]. Reduced activity in response to fetal hypoxic distress is used for the biophysical profile as part of an objective antepartum assessment in high-risk obstetric cases [13]. Though of clear benefit during a hypoxic event, this strategy is by no means a lasting solution for a chronic reduction in oxygen availability. The primary energy-consuming process in the developing fetus is growth. Within several hours of reduced fetal oxygen delivery, protein synthesis begins to decline, reducing systemic oxygen consumption [14]. This sacrifice in the battle to maintain equilibrium of oxygen flux will cause intrauterine growth retardation so that survival will be at the cost of low birth weight and the possibility of organ pathology. Of note, chronic maternal hypoxia due to residence at high altitude is associated with reduced birth weight from restricted fetal growth during the third trimester [15]. Thus, fetal survival is ensured by entering a period of hibernation-like existence in which oxygenconsuming processes are downregulated in order to avoid anaerobic respiration. Clearly, there will be a threshold below which this strategy leads to irreversible organ damage.

Transition from uterine to atmospheric life involves the loss of mechanisms imperative for fetal survival but redundant in the relatively oxygen-rich air ex utero. To facilitate this, the lungs supervene over the placenta as the gas exchange surface, and there is anatomical redistribution of blood flow. Within weeks, the hemoglobin concentration of the neonate slowly declines and production of fetal hemoglobin ( $\mathrm{HbF})$, which possesses considerably greater affinity for oxygen than does adult hemoglobin, ceases. Yet these and other mechanisms would surely be advantageous to adults during hypoxemic events. The retention of life-sustaining fetal phenomena was first demonstrated by the French physiologist Paul Bert some 140 years ago. Bert observed that newborn rats, when submersed in water, maintained persistent respiratory movements for up to 30 minutes, yet at 20 days of age, similar rats ceased to breathe after only 90 seconds [16]. It is feasible that the fetus, having developed in an environment with such limited oxygen availability, retains a degree of 'acclimatization' in neonatal life. The prolonged hypoxemia in utero may serve as a time of intense 'hypoxic preconditioning' that provides a degree of protection from untoward obstetric catastrophes. However, as with climbers returning from the mountains, this acclimatization effect subsides with time, as shown by reduced resistance to hypoxia with increasing neonatal age.

Historically, life on Earth has also been one of extreme hypoxia. The Earth was formed approximately 4.6 billion years ago and the earliest life-forms appeared soon after the planet's period of heavy bombardment from meteorites, 4 billion years ago. At that time, the atmosphere consisted of gases released from within the Earth's crust, primarily nitrogen, carbon dioxide, water vapor, and hydrogen, the last of which was light enough to escape the Earth's gravitational force. To the primitive anaerobic prokaryotes that first inhabited the Earth, even traces of oxygen were highly toxic. Through the photochemical destruction of water vapor, releasing oxygen and hydrogen, and then photosynthesis by cyanobacteria, the concentration of oxygen in the atmosphere rose and organisms were forced to adapt to shield themselves from its destructive power. Two billion years ago, a process known as eukaryotic endosymbiosis occurred in which mitochondria, evolved from a strain of purple bacteria, were engulfed by prokaryotic cells but retained their 
functional capacity. This unique combination provided a hypoxic sanctuary for the anaerobic-seeking mitochondria and a source of energy for the host cell, in the form of ATP, which allowed the development of eukaryotic characteristics and eventually multicellular aerobic life.

Our understanding of the human response to hypoxia has developed considerably since Barcroft's day. The heterodimeric protein hypoxia-inducible factor 1 (HIF-1) plays a central role in maintaining oxygen homeostasis. Cellular hypoxia results in reduced degradation by prolyl hydroxylase (PHD) and an exponential rise of the HIF- $1 \alpha$ subunit, which combines with the constitutively expressed HIF-1 $\beta$ subunit to form the active transcription factor. This triggers upregulation of erythropoietin, angiogenic factors, and vasoactive mediators to improve oxygen delivery while induction of glycolytic enzymes permits continued energy production when oxygen for oxidative phosphorylation is scarce. Additionally, HIF-1 depresses mitochondrial oxygen consumption and improves the efficiency of energy production within mitochondria $[17,18]$. During chronic fetal hypoxia, levels of HIF- $1 \alpha$ are significantly increased [19] while a deficiency of either the $\alpha$ or $\beta$ subunits in murine models is incompatible with embryonic life [20].

Another component of an individual's 'hypoxic response fingerprint' is the seemingly paradoxical mitochondrial production of reactive oxygen species (ROS) by enzymes of the respiratory chain when oxygen is scarce [21]. Elevated concentrations of ROSs have been detected in the cord blood of profoundly hypoxic neonates at birth [22]. These highly reactive molecules, if left unchecked, can cause extensive cellular oxidative damage and apoptosis. However, mitochondrial ROSs are also required during adaptation to hypoxia as they promote transcription via HIF-1 [23] with concomitant negative feedback from HIF-1 attenuating ROS generation [24]. ROS production is also governed partly by uncoupling proteins (UCPs) on the inner mitochondrial membrane, allowing a leak of protons without the generation of energy [25]. Thus, ROSs and UCPs act together to initiate cellular signaling during cellular hypoxia. This contends the liberal use of antioxidants in hypoxic critically ill patients and may provide an axis for future interventions aimed at manipulating hypoxia tolerance in adults.

As well as being a key component in the maintenance of vascular tone, nitric oxide (NO) is a fundamental cellular messenger with an important role in the regulation of fetal and adult biology. Fetal levels of NO metabolites are raised in the presence of intrauterine growth retardation, particularly when fetal oxygenation is compromised [26]. Not only does hypoxia stimulate increased release of NO from vascular endothelium, but under conditions of cellular hypoxia, mitochondria themselves can produce NO, which may represent part of the cellular hypoxia-sensing apparatus [27]. The potential significance of this metabolite is highlighted in highaltitude resident Tibetans, whose circulating concentrations of bioactive NO products are 10 times higher than those of low-altitude dwellers [28]. In fact, the authors of this study stated that the plasma nitrite and nitrate concentrations of Tibetans were unprecedented for healthy people and that average concentrations exceeded those typically seen in septic shock patients' [28]. This poses an interesting conundrum. In the Tibetans, high circulating NO metabolites appear to be beneficial, whereas in critically ill patients, it may represent a maladaptive phenomenon that leads to circulatory catastrophe. Interestingly, $\mathrm{HbF}$ displays an NO-scavenging effect that is greater than that of adult hemoglobin [29], which may account for the apparent circulatory stability within the fetus in the face of severe hypoxemia.

\section{In utero to intensive care}

The ability of the fetus to withstand profound and sustained hypoxia in utero may serve as a model from which to develop strategies to improve survival in hypoxemic critically ill adults (Figure 1). With a better understanding of the relationship between hypoxemia and tissue hypoxia, 'permissive hypoxemia' could become a realistic possibility in selected patient cohorts. Simply adding more oxygen at the top of the oxygen cascade may not be the solution to disequilibrium at a tissue level. Furthermore, the toxic potential of oxygen is frequently understated despite mounting evidence in animal models and human studies [30-33]. A recent multicenter cohort study of over 6,000 patients who had sustained a nontraumatic cardiac arrest demonstrated that those patients who were hyperoxic (defined as a $\mathrm{PaO}_{2}$ of greater than $40 \mathrm{kPa}$ ) had a significantly higher in-hospital mortality rate when compared with normoxic or hypoxic patients [34]. In the current clinical climate of goal-directed oxygen delivery, the degree to which chronic hypoxemia should be corrected remains unknown. With accumulating evidence that normoxia may not be a prerequisite for survival or successful recovery, the possibility of permitting selected patients to remain hypoxic consequent upon their disease process may not be as absurd as it initially appears. The damage caused by high concentrations of inspired oxygen and aggressive mechanical ventilation protocols has promoted this philosophy among pediatric critical care physicians [35]. With more reliable monitors of specific tissue oxygenation, such as near-infrared spectroscopy, we might begin to relinquish our deep-rooted need to fully correct hypoxemia.

One group of authors has elegantly highlighted how rethinking our perceptions of oxygenation has the potential to revolutionize patient care [36,37]. In two meta-analyses, they questioned the evidence base for the 


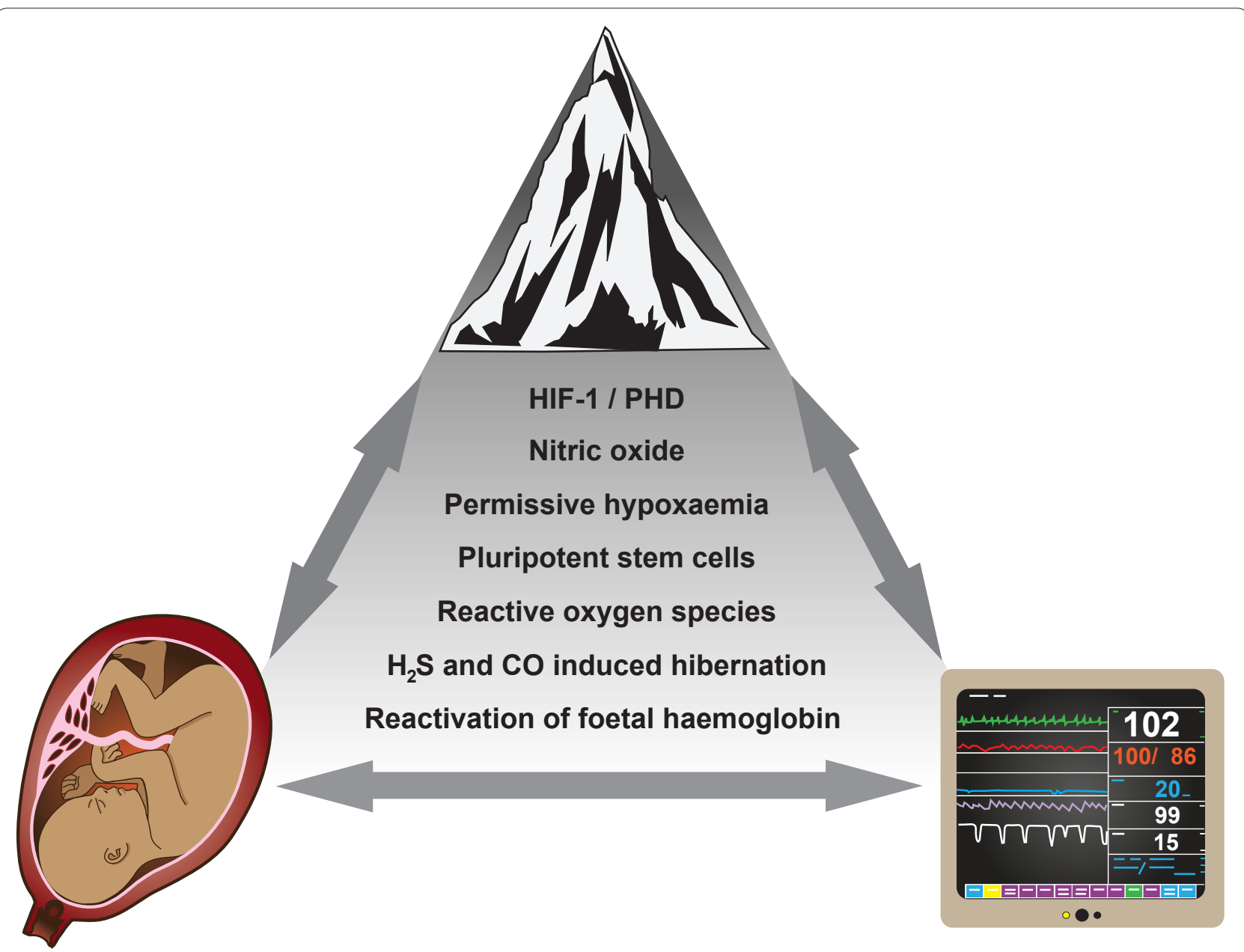

Figure 1. Therapy for hypoxemic critically ill adults: potential therapeutic targets derived from translational work in fetal and highaltitude research. $\mathrm{CO}$, carbon monoxide; $\mathrm{H}_{2} \mathrm{~S}$, hydrogen sulphide; $\mathrm{HIF-1}$, hypoxia-inducible factor 1 ; PHD, prolyl hydroxylase.

universal practice of supplemental oxygen administration during acute myocardial infarction, reporting a striking association between high inspired oxygen concentrations and reduced coronary blood flow, greater infarct size, and a potentially increased risk of mortality [36,37]. Conversely, intracoronary transfer of autologous bone marrow cells has already been shown to promote improvement of left ventricular systolic function after acute myocardial infarction [38]. The use of stem cells in targeted regenerative medicine is likely to play a major part in future interventions. Reprogramming of adult cell lines by transduction of transcription factors can generate induced pluripotent stem cells (iPSCs). Hypoxia not only enhances the generation of iPSCs [39] but also promotes the renewal of stem cells via HIF-mediated pathways [40]. Is this a window into the body's own attempts at regeneration and repair in response to hypoxia, and can we mimic such repair mechanisms?

Owing to an oxygen-carrying capacity greater than that of adult hemoglobin, $\mathrm{HbF}$ enhances the transport of oxygen across the placenta from the maternal circulation. Consisting of $\alpha_{2} \gamma_{2}$ subunits rather than $\alpha_{2} \beta_{2}$ possessed by most healthy adults, $\mathrm{HbF}$ has a lower affinity for 2,3-diphosphoglycerate than adult hemoglobin does, therefore causing a leftwards-shifted oxygen-hemoglobin dissociation curve. This accounts for the greater measured $\mathrm{SaO}_{2}$ for any given $\mathrm{PaO}_{2}$ in fetal, as compared with maternal, blood. In those born with sickle cell disease, HbF production continues in adult life, optimizing arterial oxygen content. So significant is the persistence of this fetal mechanism that a low level of $\mathrm{HbF}$ in sickle cell patients is an independent predictor of early mortality [41] and pharmacologically increasing $\mathrm{HbF}$ concentration with hydroxyurea improves long-term outcome in this patient cohort [42], possibly via an NOmediated pathway [43]. Humans homozygous for the genetic disorder 'hereditary persistence of fetal hemoglobin' express $\gamma$-globin only and thus all of their circulating hemoglobin is of the fetal species [44]. This benign condition also exists in variety of heterozygous 
forms and is more common in those populations in which $\beta$-hemoglobinopathies are prevalent [45]. As the presence of high circulating quantities of $\mathrm{HbF}$ appears to be without detrimental effect, pharmacological reactivation of the $\gamma$-globin and $\mathrm{HbF}$ in adult erythroid cells during chronic hypoxemia seems feasible. The growthmodifying cytokine, stem cell factor, in combination with erythropoietin, leads to increased production of $\mathrm{HbF}$ in animal models [46]. Genetic manipulation of the switching mechanism between $\beta$ - and $\gamma$-globin at DNA transcription or via alteration of $\gamma$-globin mRNA transcription, translation, and post-translational events might allow adults to revert to a fetal oxygen-carrying modality.

It has been proposed that the multiple organ failure witnessed in severe critical illness may represent a rudimentary reduction in mitochondrial oxygen consumption in order to preserve organs when faced with a life-threatening challenge [47]. This is analogous to the strategy adopted by the fetus in times of distress and the concept may hold the key to an alternative approach to managing severe hypoxemia. Hydrogen sulphide $\left(\mathrm{H}_{2} \mathrm{~S}\right)$ is an endogenously produced signaling molecule that belongs to a trio of biological mediators, including NO and carbon monoxide (CO), referred to as gasotransmitters [48]. $\mathrm{H}_{2} \mathrm{~S}$ is known to influence cellular metabolism via cytochrome oxidase and carbonic anhydrase and interaction with reactive oxygen and nitrogen species (leading to free radical scavenging). It also causes activation of ATP-sensitive potassium $\left(\mathrm{K}_{\mathrm{ATP}}\right)$ channels and modification of gene transduction [49]. Low concentrations of $\mathrm{H}_{2} \mathrm{~S}$ exert a cytoprotective effect, whereas higher concentrations have the more commonly appreciated cytotoxic properties, primarily via mitochondrial failure. The relevance of $\mathrm{H}_{2} \mathrm{~S}$ to critical care medicine is that, when used in carefully titrated doses, it has the ability to induce a state of hibernation in animal models [50-52]. In such a state of torpor, the organism undergoes a reversible reduction in energy-consuming processes that facilitates a reduction in both oxygen uptake and delivery, therefore protecting tissues from oxygen deprivation. When mice are exposed to $\mathrm{H}_{2} \mathrm{~S}$ gas, they undergo a doserelated reduction in metabolic, heart, and respiratory rates for a period of several hours [50]. This permits the tolerance of severe and prolonged hypoxia without detrimental effects [53]. Basal $\mathrm{H}_{2} \mathrm{~S}$ production has been demonstrated in fetal membranes, and there is a significant upregulation when the tissues are exposed to low levels of oxygen in vitro [54]. This hypoxia-induced elevation in $\mathrm{H}_{2} \mathrm{~S}$ may represent a primitive protective mechanism that serves to downregulate metabolism during times of stress, a step beyond the simple reduction of fetal movements observed following acute oxygen deprivation in utero. $\mathrm{CO}$ can also protect against hypoxic damage by interacting with HIF-1-induced pathways to induce a state of 'suspended animation' [55]. Furthermore, hypoxia promotes the endogenous production of $\mathrm{CO}$ via haem oxygenase- 1 , a process that prevents hypoxic damage through a variety of anti-inflammatory and anti-apoptotic mechanisms [56]. The question of whether humans safely enter a state of reversible suspended animation remains. Sporadic case reports provide circumstantial evidence that prolonged hypothermia and hypoxemia can be tolerated without detrimental effects [57]. Induced suspended animation has also been proposed as a viable strategy following cardiac arrest [50] and during severe sepsis [58]. The possibility of pharmacologically induced hibernation in the critically ill would be as revolutionary as the iron lung, diverting the focus of oxygen supply-demand coupling to the latter rather than the former.

The pivotal role of HIF in oxygen sensing and hypoxic adaptation also makes it a prime target for interventional studies. Already, work on specific inhibitors of PHD has been shown to induce hypoxic adaption [59]. In combination with other components of the cellular hypoxic response, such as regulators of the NO pathway and UCPs, these alternative strategies may avoid therapeutic interventions that resort to the administration of toxic concentrations of oxygen. Crosstalk between the HIF-1 transcription pathway and the ROS cascade should provide a wealth of targets for future pharmacological interventions.

Mastery of human cellular adaptation to hypoxia may be feasible in the paradigm of scientifically robust highaltitude research $[60,61]$. The inter-individual variation in human performance at high altitude [62] mirrors that expressed in the hypoxemic environment experienced during critical illness. This alternative methodological approach to hypoxia research could lead to novel translational studies in critically ill patients. Exposure of healthy individuals to graded 'doses' of hypoxia provides a platform from which physiological mechanisms of adaptation and effects of their perturbation can be observed in whole-body systems. It holds further advantage in controlling for the unfavorable 'signal-to-noise ratio' that is often encountered in the study of patient populations with multiple pathologies. Our current understanding of the process of acclimatization to high altitude focuses on restoration of normal sea level systemic oxygen delivery via increases in minute ventilation, cardiac output, and red blood cell mass. However, as in survival in utero, the mechanisms that separate survivors from non-survivors may lie in the cellular control of oxygen consumption via the signaling pathways discussed. Indigenous populations living at high altitudes have the advantage of lasting biological changes as a result of the evolutional pressure exerted by hypobaric hypoxia. Their capacity for systemic oxygen 
carriage is no greater than that of an acclimatized 'lowlander' [3,63], thus suggesting more intricate changes with thousands of years of evolution, making their physiology more akin to that of the fetus.

\section{Conclusions}

Human organ systems have developed in an oxygendeprived environment during fetal life. This brief developmental era is easily forgotten when we consider adaptation to hypoxemia yet it may well hold the key to our most sophisticated compensatory mechanisms, with a potential for reawakening in disease states. The complex network of cellular signaling pathways that act to detect hypoxia and preserve cellular functioning in utero may be the answer to the failure of the systemic delivery of oxygen to tissues. Manipulation of gasotransmitters to promote adaptation to hypoxemia may avoid the detrimental effects of excessive oxygen administration. All of us are triumphant mountaineers of Barcroft's Everest in utero and the sequeale of that expedition may return to save us in our hour of need.

\section{Abbreviations}

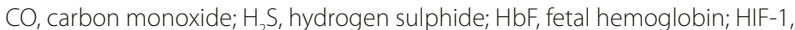
hypoxia-inducible factor 1 ; iPSC, induced pluripotent stem cell; NO, nitric oxide; $\mathrm{PaO}_{2}$, partial pressure of oxygen; $\mathrm{PHD}$, prolyl hydroxylase; $\mathrm{ROS}$, reactive oxygen species; $\mathrm{SaO}_{2^{\prime}}$ arterial oxygen saturation; UCP, uncoupling protein.

\section{Competing interests}

The authors declare that they have no competing interests.

\section{Acknowledgments}

Some of this work was undertaken at the University College London Hospital University College London Comprehensive Biomedical Research Centre, which received a portion of funding from the funding scheme of the UK Department of Health's National Institute for Health Research biomedical research centres.

\section{Author details}

'Centre for Altitude, Space and Extreme Environment Medicine, Portex Unit, University College London (UCL) Institute of Child Health, 30 Guilford Street, London, WC1N 1EH, UK. ${ }^{2}$ UCL Centre for Anaesthesia, Anaesthetics Department, Podium 3, Maple Link corridor, University College Hospital, 235 Euston Road, London, NW1 2BU, UK. ${ }^{3}$ Southampton University Hospital NHS Trust, Tremona Road, Southampton, SO 16 6YD, UK. ${ }^{4}$ UCL Hospitals/ UCL Comprehensive Biomedical Research Centre, 1st Floor, Maple House, 149 Tottenham Court Road, London, W1T 7NF, UK.

Published: 30 July 2010

\section{References}

1. Barcroft J: Researches in Perinatal Life. Oxford, UK: Blackwell; 1946.

2. Eastman NJ: Mount Everest in utero. Am J Obstet Gynecol 1954, 67:701-711.

3. Grocott MP, Martin DS, Levett DZ, McMorrow R, Windsor J, Montgomery HE: Arterial blood gases and oxygen content in climbers on Mount Everest. NEngl J Med 2009, 360:140-149.

4. Richardson BS, Bocking AD: Metabolic and circulatory adaptations to chronic hypoxia in the fetus. Comp Biochem Physiol A Mol Integr Physiol 1998, 119:717-723.

5. Meschia G: Placenta respiratory gas exchange and fetal oxygenation. In Maternal Fetal Medicine: Principles and Practice. 1st edition. Edited by Creasy RK, Resnik R. Philadelphia, PA: WB Saunders; 1987:274-285.

6. West JB: Arterial blood measurements in climbers on Mount Everest. Lancet 2009, 373:1589-1590.

7. Battaglia FC, Meschia G: Principal substrates of fetal metabolism. Physio/ Rev 1978, 58:499-527.
8. Itskovitz J, LaGamma EF, Rudolph AM: The effect of reducing umbilical blood flow on fetal oxygenation. Am J Obstet Gynecol 1983, 145:813-818.

9. Jensen A, Garnier Y, Berger R: Dynamics of fetal circulatory responses to hypoxia and asphyxia. Eur J Obstet Gynecol Reprod Biol 1999, 84:155-172.

10. Boddy K, Dawes GS, Fisher R, Pinter S, Robinson JS: Foetal respiratory movements, electrocortical and cardiovascular responses to hypoxaemia and hypercapnia in sheep. J Physiol 1974, 243:599-618.

11. Natale R, Clewlow F, Dawes GS: Measurement of fetal forelimb movements in the lamb in utero. Am J Obstet Gynecol 1981, 140:545-551.

12. Rurak DW, Gruber NC: The effect of neuromuscular blockade on oxygen consumption and blood gases in the fetal lamb. Am J Obstet Gynecol 1983, 145:258-262.

13. Manning FA, Platt LD, Sipos L: Antepartum fetal evaluation: development of a fetal biophysical profile. Am J Obstet Gynecol 1980, 136:787-795.

14. Milley JR: Protein synthesis during hypoxia in fetal lambs. Am J Physio/ 1987, 252:E519-24.

15. Moore LG: Fetal growth restriction and maternal oxygen transport during high altitude pregnancy. High Alt Med Biol 2003, 4:141-156.

16. Bert P: Lecons sur la Physiologie Comparee de la Respiration. Paris: Bailliere; 1870.

17. Papandreou I, Cairns RA, Fontana L, Lim AL, Denko NC: HIF-1 mediates adaptation to hypoxia by actively downregulating mitochondrial oxygen consumption. Cell Metab 2006, 3:187-197.

18. Fukuda R, Zhang H, Kim JW, Shimoda L, Dang CV, Semenza GL: HIF-1 regulates cytochrome oxidase subunits to optimize efficiency of respiration in hypoxic cells. Cell 2007, 129:111-122.

19. Martin C, Yu AY, Jiang BH, Davis L, Kimberly D, Hohimer AR, Semenza GL: Cardiac hypertrophy in chronically anemic fetal sheep: increased vascularization is associated with increased myocardial expression of vascular endothelial growth factor and hypoxia-inducible factor 1. Am J Obstet Gynecol 1998, 178:527-534.

20. Schumacker PT: Hypoxia-inducible factor-1 (HIF-1). Crit Care Med 2005, 33:\$423-5

21. Duranteau J, Chandel NS, Kulisz A, Shao Z, Schumacker PT: Intracellular signaling by reactive oxygen species during hypoxia in cardiomyocytes. J Biol Chem 1998, 273:11619-11624.

22. Wang W, Pang CC, Rogers MS, Chang AM: Lipid peroxidation in cord blood at birth. Am J Obstet Gynecol 1996, 174:62-65.

23. Chandel NS, Maltepe E, Goldwasser E, Mathieu CE, Simon MC, Schumacker PT: Mitochondrial reactive oxygen species trigger hypoxia-induced transcription. Proc Natl Acad SciU S A 1998, 95:11715-11720.

24. Weidemann A, Johnson RS: Biology of HIF-1alpha. Cell Death Differ 2008, 15:621-627.

25. Casteilla L, Rigoulet M, Penicaud L: Mitochondrial ROS metabolism: modulation by uncoupling proteins. IUBMB Life 2001, 52:181-188.

26. Tikvica A, Kusan Jukic M, Pintaric I, Medic M, Hudicek-Martincic G, Kosec V, Salihagic-Kadic A: Nitric oxide synthesis in placenta is increased in intrauterine growth restriction and fetal hypoxia. Coll Antropol 2008 32:565-570.

27. Castello PR, David PS, McClure T, Crook Z, Poyton RO: Mitochondrial cytochrome oxidase produces nitric oxide under hypoxic conditions: implications for oxygen sensing and hypoxic signaling in eukaryotes. Cell Metab 2006, 3:277-287

28. Erzurum SC, Ghosh S, Janocha AJ, Xu W, Bauer S, Bryan NS, Tejero J, Hemann C, Hille R, Stuehr DJ, Feelisch M, Beall CM: Higher blood flow and circulating NO products offset high-altitude hypoxia among Tibetans. Proc Natl Acad SciUSA 2007, 104:17593-17598.

29. Calatayud S, Beltran B, Brines J, Moncada S, Esplugues JV: Foetal erythrocytes exhibit an increased ability to scavenge for nitric oxide. Eur J Pharmacol 1998, 347:363-366

30. Crapo JD, Hayatdavoudi G, Knapp MJ, Fracica PJ, Wolfe WG, Piantadosi CA: Progressive alveolar septal injury in primates exposed to $60 \%$ oxygen for 14 days. Am J Physiol 1994, 267:L797-806.

31. Fracica PJ, Knapp MJ, Piantadosi CA, Takeda K, Fulkerson WJ, Coleman RE, Wolfe WG, Crapo JD: Responses of baboons to prolonged hyperoxia: physiology and qualitative pathology. J Appl Physiol 1991, 71:2352-2362.

32. de Jonge $E$, Peelen $L$, Keijzers $P J$, Joore $H$, de Lange $D$, van der Voort PH, Bosman RJ, de Waal RA, Wesselink R, de Keizer NF: Association between administered oxygen, arterial partial oxygen pressure and mortality in mechanically ventilated intensive care unit patients. Crit Care 2008, 12:R156.

33. Baleeiro CE, Wilcoxen SE, Morris SB, Standiford TJ, Paine R 3rd: Sublethal hyperoxia impairs pulmonary innate immunity. J Immunol 2003, 
171:955-963.

34. Kilgannon JH, Jones AE, Shapiro NI, Angelos MG, Milcarek B, Hunter K, Parrillo $J$ E, Trzeciak S: Association between arterial hyperoxia following resuscitation from cardiac arrest and in-hospital mortality. JAMA 2010, 303:2165-2171.

35. Cheifetz IM, Hamel DS: Is permissive hypoxemia a beneficial strategy for pediatric acute lung injury? Respir Care Clin N Am 2006, 12:359-369, v-vi.

36. Farquhar $H$, Weatherall $M$, Wijesinghe $M$, Perrin $K$, Ranchord $A$, Simmonds $M$, Beasley R: Systematic review of studies of the effect of hyperoxia on coronary blood flow. Am Heart J 2009, 158:371-377.

37. Wijesinghe M, Perrin K, Ranchord A, Simmonds M, Weatherall M, Beasley R: Routine use of oxygen in the treatment of myocardial infarction: systematic review. Heart 2009, 95:198-202.

38. Wollert KC, Meyer GP, Lotz J, Ringes-Lichtenberg S, Lippolt P, Breidenbach C, Fichtner S, Korte T, Hornig B, Messinger D, Arseniev L, Hertenstein B, Ganser A, Drexler $\mathrm{H}$ : Intracoronary autologous bone-marrow cell transfer after myocardial infarction: the BOOST randomised controlled clinical trial. Lancet 2004, 364:141-148.

39. Yoshida Y, Takahashi K, Okita K, Ichisaka T, Yamanaka S: Hypoxia enhances the generation of induced pluripotent stem cells. Cell Stem Cell 2009, 5:237-241.

40. Keith B, Simon MC: Hypoxia-inducible factors, stem cells, and cancer. Cell 2007, 129:465-472

41. Platt OS, Brambilla DJ, Rosse WF, Milner PF, Castro O, Steinberg MH, Klug PP: Mortality in sickle cell disease. Life expectancy and risk factors for early death. NEngl J Med 1994, 330:1639-1644.

42. Goldberg MA, Brugnara C, Dover GJ, Schapira L, Charache S, Bunn HF: Treatment of sickle cell anemia with hydroxyurea and erythropoietin. NEngl J Med 1990, 323:366-372.

43. Cokic VP, Smith RD, Beleslin-Cokic BB, Njoroge JM, Miller JL, Gladwin MT, Schechter AN: Hydroxyurea induces fetal hemoglobin by the nitric oxidedependent activation of soluble guanylyl cyclase. J Clin Invest 2003, 111:231-239.

44. Forget BG: Molecular basis of hereditary persistence of fetal hemoglobin. Ann N Y Acad Sci 1998, 850:38-44

45. Friedman S, Schwartz E: Hereditary persistence of foetal haemoglobin with beta-chain synthesis in cis position (Ggamma-beta+-HPFH) in a negro family. Nature 1976, 259:138-140.

46. Lavelle D, Molokie R, Ducksworth J, DeSimone J: Effects of hydroxurea, stem cell factor, and erythropoietin in combination on fetal hemoglobin in the baboon. Exp Hematol 2001, 29:156-162

47. Singer $M$, De Santis V, Vitale $D$, Jeffcoate $W$ : Multiorgan failure is an adaptive, endocrine-mediated, metabolic response to overwhelming systemic inflammation. Lancet 2004, 364:545-548.

48. Wang R: The gasotransmitter role of hydrogen sulfide. Antioxid Redox Signal 2003, 5:493-501.
49. Szabo C: Hydrogen sulphide and its therapeutic potential. Nat Rev Drug Discov 2007, 6:917-935.

50. Blackstone $\mathrm{E}$, Morrison M, Roth MB: H2S induces a suspended animationlike state in mice. Science 2005, 308:518.

51. Carey HV, Andrews MT, Martin SL: Mammalian hibernation: cellular and molecular responses to depressed metabolism and low temperature. Physiol Rev 2003, 83:1153-1181.

52. Dausmann KH, Glos J, Ganzhorn JU, Heldmaier G: Physiology: hibernation in a tropical primate. Nature 2004, 429:825-826.

53. Blackstone $E$, Roth MB: Suspended animation-like state protects mice from lethal hypoxia. Shock 2007, 27:370-372.

54. Patel P, Vatish M, Heptinstall J, Wang R, Carson RJ: The endogenous production of hydrogen sulphide in intrauterine tissues. Reprod Biol Endocrinol 2009, 7:10.

55. Nystul TG, Roth MB: Carbon monoxide-induced suspended animation protects against hypoxic damage in Caenorhabditis elegans. Proc Natl Acad SciU S A 2004, 101:9133-9136.

56. Dulak J, Jozkowicz A: Carbon monoxide -- a "new" gaseous modulator of gene expression. Acta Biochim Pol 2003, 50:31-47.

57. Roth MB, Nystul T: Buying time in suspended animation. Sci Am 2005 292:48-55

58. Protti A, Singer M: Bench-to-bedside review: potential strategies to protect or reverse mitochondrial dysfunction in sepsis-induced organ failure. Crit Care 2006, 10:228.

59. Warnecke C, Griethe W, Weidemann A, Jurgensen JS, Willam C, Bachmann S, Ivashchenko Y, Wagner I, Frei U, Wiesener M, Eckardt KU: Activation of the hypoxia-inducible factor-pathway and stimulation of angiogenesis by application of prolyl hydroxylase inhibitors. FASEB J 2003, 17:1 186-1188.

60. Grocott M, Montgomery H, Vercueil A: High-altitude physiology and pathophysiology: implications and relevance for intensive care medicine. Crit Care 2007, 11:203.

61. Martin D, Windsor J: From mountain to bedside: understanding the clinical relevance of human acclimatisation to high-altitude hypoxia. Postgrad Med J 2008, 84:622-627.

62. Martin DS, Levett DZ, Grocott MP, Montgomery HE: Variation in human performance in the hypoxic mountain environment. Exp Physio/ 2010, 95:463-470.

63. Beall CM: Andean, Tibetan, and Ethiopian patterns of adaptation to highaltitude hypoxia. Integr Comp Biol 2006, 46:18-24.

doi:10.1186/cc9078

Cite this article as: Martin DS, et al.: Concepts in hypoxia reborn. Critical Care 2010, 14:315. 